\title{
Spontaneous and induced chromosome breakage in chorionic villus samples: a cytogenetic approach to first trimester prenatal diagnosis of ataxia telangiectasia syndrome
}

\author{
JUAN LLERENA JR, MANUELA MURER-ORLANDO, MARY McGUIRE, \\ LAILA ZAHED, RICHARD J SHERIDAN, A CAROLINE BERRY, \\ AND MARTIN BOBROW
}

From the Paediatric Research Unit, Division of Medical and Molecular Genetics, United Medical and Dental Schools of Guy's and St Thomas's Hospitals, Guy's Hospital, London SE1 9RT.

SUMmaRY Patients with ataxia telangiectasia (AT) syndrome exhibit a high level of spontaneous chromosome aberrations, with hypersensitivity to gamma radiation and radiomimetic chemicals at the chromosomal and cellular level.

Previously pregnancies at risk for AT have been screened solely by analysis of amniotic fluid samples. In this report we describe a cytogenetic approach to the prenatal diagnosis of AT using chorionic villus sampling (CVS).

Levels of spontaneous and induced (gamma radiation and bleomycin) chromosome breakage were established in direct, semidirect, and culture preparations of CVS samples from normal pregnancies. The methods developed were then successfully applied to the screening of a pregnancy at risk for AT. Semidirect preparations showed normal levels of chromosome breakage, and this result was further confirmed in chorion, amniotic fluid, and lymphocyte cultures. In chorion villus samples, gamma radiation is probably the easiest and most reliable way of discriminating between unaffected fetuses and those with AT.

Ataxia telangiectasia (AT), one of the rare autosomal recessive diseases known as 'chromosome instability disorders', is characterised clinically by cerebellar ataxia, oculocutaneous telangiectasia, humoral and cellular immunodeficiency, and an increased predisposition to cancer. ${ }^{1-3}$ Affected subjects are also particularly sensitive to ionising radiation. ${ }^{4}$ Data from cell fusion experiments and DNA synthesis after gamma radiation, in different AT cells strains, have showed the extensive genetic heterogeneity of the disease, and at least five complementation groups have also been identified. ${ }^{5-7}$

However, the generally accepted hallmarks of AT are: (1) a tendency to exhibit a high level of spontaneous chromosome aberrations; (2) the presence of stable chromosome rearrangements involving chromosomes 7, 14, and X in clonal cells; (3) hypersensitivity to gamma radiation and radiomimetic chemicals at the chromosomal and cellular level. ${ }^{8-11}$

Received for publication 13 May 1988.

Revised version accepted for publication 11 August 1988.
Pregnancies at risk for AT have been monitored by screening second trimester amniotic fluid (AF) samples for chromosome instability and biochemical abnormalities. ${ }^{12-15}$ At least two fetuses have been diagnosed as affected, and the pregnancies terminated. ${ }^{13}{ }^{15}$ The parents of affected patients run 윽 a $25 \%$ risk of recurrence in any future pregnancy, $\rightarrow$ and they would benefit greatly if first trimester prenatal diagnosis became available, as early ter- N mination of an affected pregnancy would then be possible. Chorionic villus sampling (CVS) is an $\tilde{O}$ alternative procedure for the prenatal diagnosis of $\mathrm{N}_{\mathrm{W}}$ chromosome abnormalities and can be performed $\widetilde{\sigma}$ in the early stages of pregnancy. ${ }^{16}{ }^{17}$ Fetuses at risk 0 for Fanconi's anaemia, another chromosome instability disorder, have already been screened $\stackrel{\infty}{\rightarrow}$ successfully in the first trimester of pregnancy using $T$ direct, ${ }^{18}$ semidirect, ${ }^{19}$ and culture ${ }^{18} 20$ preparations $\frac{D}{D}$ from chorion biopsies.

In this report we describe the first cytogenetic $\stackrel{\mathbb{Q}}{\mathscr{Q}}$ approach to the prenatal diagnosis of AT using $\bar{\sigma}$ CVS. The level of spontaneous and induced 
chromosome abnormalities was established in direct, semidirect, and culture preparations from normal CVS samples which had been exposed to gamma radiation and bleomycin (BLM) treatments. Data from these studies were then used to screen a first trimester pregnancy at risk for AT syndrome, and CVS results were eventually confirmed by analysis of amniotic fluid and lymphocyte cultures.

\section{Methods}

CHORIONIC VILLUS SAMPLES

Twenty samples from elective first trimester terminations for non-genetic reasons were used as normal controls. The at risk sample was obtained transcervically ${ }^{21}$ from the patient, a 39 year old woman who had been referred to the CVS Clinic (Paediatric Research Unit, Guy's Hospital) at nine and a half weeks' gestation in her third pregnancy. Her two previous pregnancies had resulted in the birth of two children with the typical clinical and cytogenetic features of AT. She and her husband were not related.

Direct (sample processed two hours after biopsy), ${ }^{22}$ semidirect (sample processed after overnight incubation in 10\% RPMI complete culture medium), ${ }^{23}$ and culture (conventional fibroblast culture) preparations ${ }^{24}$ of chorionic villi were obtained following standard protocols. Semidirect samples were irradiated ( 25 rads and 50 rads) or incubated with BLM $\left(10^{-4} \mu \mathrm{g} / \mathrm{ml}\right.$ to $\left.0.5 \mu \mathrm{g} / \mathrm{ml}\right)$, either six or three hours before harvesting. Early passage cultures were treated during the last six hours, either with gamma radiation (50 rads and 100 rads), or with BLM (final concentration $0.01 \mu \mathrm{g} / \mathrm{ml}$ and 0.001 $\mu \mathrm{g} / \mathrm{ml})$. The baseline chromosome breakage rate was calculated from untreated material.

\section{AMNIOTIC FLUID SAMPLES}

Amniocentesis was performed at 16 weeks of gestation in the at risk pregnancy. An amniotic fluid sample from a normal pregnancy was used as a control. Cultures were set up following standard protocols,${ }^{24}$ and untreated cultures were exposed to gamma radiation (50 rads and 100 rads) six hours before harvesting, ${ }^{12}$ or incubated with BLM (final concentration $0.01 \mu \mathrm{g} / \mathrm{ml}$ and $0.001 \mu \mathrm{g} / \mathrm{ml}$ ) for the last six hours of culture. Supernatants from the centrifuged amniotic fluid samples were retained for $\alpha$ fetoprotein assay.

\section{LYMPHOCYTE SAMPLES}

When the at risk pregnancy came to term, blood cultures from the neonate, both parents, and the older of the two affected sibs were set up using standard protocols, and incubated at $37^{\circ} \mathrm{C}$ for
72 hours. Except for untreated cultures, either BLM (final concentration $5 \mu \mathrm{g} / \mathrm{ml}$ ) was added 24 hours before harvesting, ${ }^{14}$ or the cultures were exposed to gamma radiation (50 rads and 100 rads) six hours before harvesting. ${ }^{12}$

\section{FIBROBLAST SAMPLES}

A fibroblast cell line, established from one of the affected sibs, was used as a positive control during preliminary experiments and in conjunction with cultures of CVS and AF samples from the pregnancy at risk. The AT cell line was subjected to gamma irradiation and BLM treatment according to the protocols outlined in the CVS culture preparation section.

Each sample from the pregnancy at risk was subjected to blind analysis, with normal control samples processed on the same day. GTG $^{25}$ and $\mathrm{QFQ}^{26}$ chromosome banding analyses were performed on each sample. Fifty Giemsa stained complete metaphases from each preparation were scored for gaps, breaks, and rearrangements (as defined by the 1978 International Standing Committee on Cytogenetic Nomenclature ${ }^{27}$ ). Gaps were not included in the mean chromosome breakage calculation and rearrangements were assessed as two breaks in each case.

\section{Results and discussion}

Normal chorion villus samples were analysed as direct (20 samples), semidirect (10 samples), and culture (10 samples) preparations, in order to establish the frequency of spontaneous chromosome abnormalities present (table 1).

Chromosome breakage in AT cells is usually induced by mutagenic treatments during either the G0/G1 or the G2 phase of the cell cycle. ${ }^{9}$ Because G0/G1 experiments can only be applied to a synchronous cell population with a well defined cell cycle, G2 treatments are usually preferable, since they are more reliable, only requiring knowledge of the G2 phase. ${ }^{12}$ Cell cycle studies of chorion villus cells have indicated a G2 phase of approximately three hours for both the spontaneously dividing and the cultured CVS cells. ${ }^{28}$

Treatment of non-synchronised chorion cultures with gamma radiation and BLM six hours before harvesting ensured a uniform result, as already observed in both normal and AT lymphocyte and fibroblast cultures. ${ }^{912}$ However, gamma irradiated semidirect CVS preparations did not show evidence of induced chromosome abnormalities when irradiation took place six hours before harvesting. A good response was achieved only when treatments were carried out three hours before harvesting. The 
reason for these different responses is not apparent to us.

The range of induced chromosome breakage established from normal CVS samples is shown in tables 1 and 2. Chromosome breaks produced by gamma radiation in each type of preparation were consistent in all normal samples. Fragments and chromatid breaks were the main abnormalities observed. Semidirect preparations proved to be more sensitive to gamma radiation than CVS cultured cells. However, AT fibroblast cultures did show a four to 20-fold increase in chromosome abnormalities when compared to both CVS preparations (table 1). Based on these results, we decided to screen the CVS sample at risk, using irradiation of 25 and 50 rads in semidirect preparations, and 50 and 100 rads in culture preparations.

The effect of BLM treatments in normal CVS preparations has been more difficult to evaluate. Inconsistent results were obtained from the analysis of semidirect preparations from 10 different samples, when they had been treated with a wide range of BLM concentrations in G2. Conversely, CVS cultured cells responded dramatically to the drug treatments, and high levels of chromosome aberrations (including pulverised cells), with very low mitotic indices, were observed when BLM was used at concentrations similar to that recommended for amniocyte cultures (table 2). ${ }^{14}$ Discrimination between AT fibroblasts and normal CVS cultures was only possible for low concentrations of the drug $\left(10^{-4} \mu \mathrm{g} / \mathrm{ml}\right.$ to $\left.10^{-2} \mu \mathrm{g} / \mathrm{ml}\right)$, when the affected cell line showed a three to eight fold increase in the number of chromosomal abnormalities (table 2). In our study, AT cells responded better to gamma radiation than to BLM treatments, and these results were in agreement with those obtained by other authors. 2930

Direct, semidirect, and culture CVS preparations from the pregnancy at risk indicated a normal female karyotype with a spontaneous chromosome breakage rate within the normal range (table 3 ). Analysis of chromosome polymorphisms by QFQ banding ruled out the possibility of maternal contamination.

Irradiated semidirect preparations, and irradiated or BLM treated culture preparations, produced similar chromosome damage to that in control CVS cells (table 3), while fibroblast cultures from the affected sib showed four to 15 times more chromo-

TABLE 1 Spontaneous and gamma radiation induced chromosome breakage per cell in normal CVS preparations*

\begin{tabular}{|c|c|c|c|c|}
\hline Method & Baseline & 25 rads & 50 rads & 100 rads \\
\hline $\begin{array}{l}\text { Direct } \\
\qquad(20 \text { samples })\end{array}$ & $0.02-0.04(0.02)(500$ cells $) \dagger$ & - & - & - \\
\hline $\begin{array}{l}\text { Semidirect } \\
\quad(10 \text { samples })\end{array}$ & $0 \cdot 00-0 \cdot 04(0 \cdot 01)(450$ cells $)$ & $0 \cdot 08-0 \cdot 24(0 \cdot 17)(300$ cells $)$ & $0 \cdot 32-0.85(0 \cdot 59)(450$ cells $)$ & $0.96-1.53(1.30)(200$ cells $)$ \\
\hline $\begin{array}{l}\text { Culture } \\
\text { (10 samples) }\end{array}$ & $0 \cdot 00-0.06(0.03)(600$ cells $)$ & - & $0 \cdot 02-0 \cdot 26(0 \cdot 15)(550$ cells $)$ & $0 \cdot 14-1 \cdot 08(0.49)(500$ cells $)$ \\
\hline $\begin{array}{l}\text { AT } 24563 / 2 \ddagger \\
\text { (positive } \\
\text { control) }\end{array}$ & $0 \cdot 08-0 \cdot 18(0 \cdot 12)(150$ cells $)$ & - & $0.84-3.40(1.64)(300$ cells $)$ & $1 \cdot 76-4 \cdot 15(2 \cdot 99)(300$ cells $)$ \\
\hline
\end{tabular}

*Semidirect and culture preparations irradiated three hours and six hours, respectively, before harvesting.

tRange, mean, and number of cells analysed.

† Six different sets of cultures analysed for each treatment.

TABLE 2 BLM induced chromosome breakage per cell in normal CVS culture preparations*.

\begin{tabular}{|c|c|c|c|c|c|}
\hline \multirow[t]{2}{*}{ Method } & \multicolumn{5}{|c|}{$B L M(\mu g / m l)$} \\
\hline & $0.5 t$ & $0.25 t$ & $0.05 t$ & 0.01 & 0.001 \\
\hline $\begin{array}{l}\text { CVS culture } \\
\text { (6 samples) }\end{array}$ & $\ddagger$ & $9 \cdot 87$ & $2 \cdot 84$ & $0 \cdot 20-1 \cdot 20(0 \cdot 71)(300$ cells $) \S$ & $0 \cdot 06-0 \cdot 20(0 \cdot 15)(300$ cells $)$ \\
\hline $\begin{array}{l}\text { AT } 24563 / 2 \| \\
\text { (positive } \\
\text { control) }\end{array}$ & $7 \cdot 54$ & $11 \cdot 25$ & $3 \cdot 57$ & $0.72-3.52(2.48)(150$ cells $)$ & $0 \cdot 32-1 \cdot 56(0 \cdot 73)(200$ cells $)$ \\
\hline \multicolumn{6}{|c|}{$\begin{array}{l}\text { *Treated six hours before harvesting. } \\
\text { †Concentrations used only in one or two experiments because of their evident cytotoxic effect in CVS samples. } \\
\text { †Low mitotic rate. } \\
\text { §Range, mean, and number of cells analysed. } \\
\text { ॥Four different sets of culture analysed for each treatment. }\end{array}$} \\
\hline
\end{tabular}


some breakage in irradiated cells, and two to five times more chromosome damage in BLM treated cultures.

An AF sample was obtained from the pregnancy at risk at 16 weeks' gestation. Alphafetoprotein levels were within normal values. Irradiated and BLM treated amniocyte cultures showed a normal female karyotype with normal levels of chromosome breakage (table 3 ).

At term, an apparently normal female was delivered. Normal chromosome sensitivity to gamma radiation and BLM treatment was shown in peripheral lymphocyte cultures (table 4). Serum $\alpha$ fetoprotein levels were within normal values.

The prenatal diagnosis of AT has previously only been investigated in amniotic fluid samples. ${ }^{15} 31$ To the best of our knowledge, this report is the first attempt to use CVS for screening first trimester pregnancies at risk for AT. Chromosome analysis of the chorionic villus sample was performed in three different ways. With the direct method, spontaneous chromosome breakage was evaluated in just a few hours from the time of sampling. The semidirect method involved the introduction of clastogenic agents, the effects of which were studied in the spontaneously dividing cells of the cytotrophoblast layer. Finally, a conventional long term fibroblast culture method was applied to the material obtained at CVS, and spontaneous and induced chromosome breakage analyses were performed nine days after sampling.

Chorionic material proved to be suitable for induced chromosome breakage studies. CVS cells showed a good response to mutagenic agents, such as gamma radiation and BLM, when treated during the $\mathrm{G} 2$ phase. Exposure to gamma radiation is probably the easiest and most reliable means of discriminating between affected and normal fetuses, since BLM treatments have proved to be more toxic to both spontaneously dividing and cultured cells from CVS.

In our study, reasonable discrimination between normal chorion samples and AT fibroblast cultures was achieved. However, we can only assume that

TABLE 3 Spontaneous and induced chromosome breakage in the pregnancy at risk.

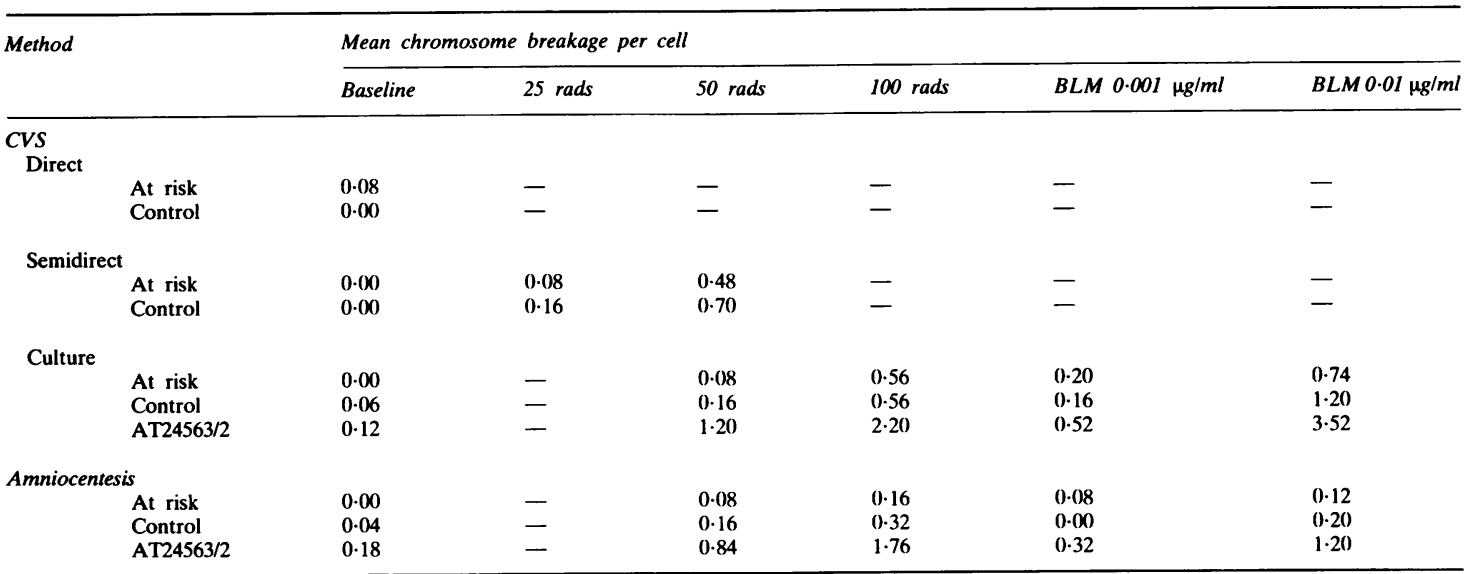

TABLE 4 Spontaneous and induced chromosome breakage in lymphocyte cultures from the family at risk.

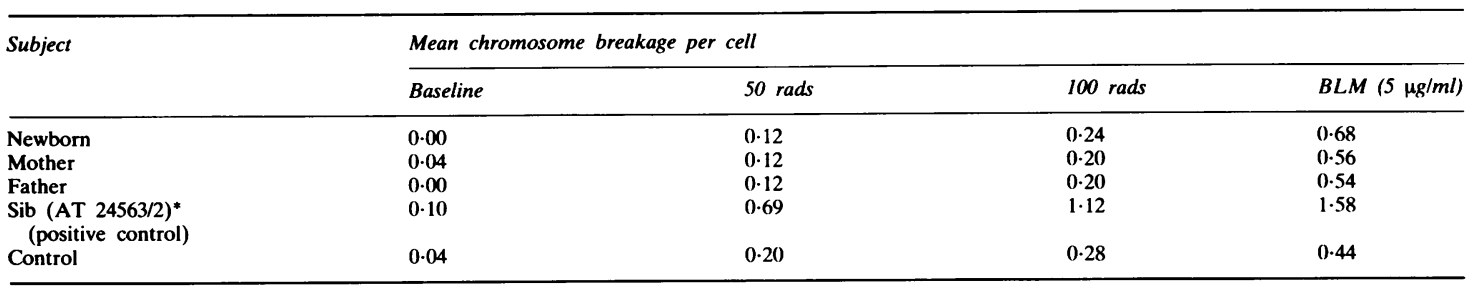

*Karyotype mos46,XY/46,XY,tct(14;14)(q32;q11.2) (20\% abnormal cells). 
our procedure is suitable for prenatal diagnosis of AT, until it has been validated by screening chorion material from an affected pregnancy.

We would like to thank Dr F Giannelli and Miss Elizabeth Manners for reviewing the manuscript, Mrs Cynthia King and Miss Elsie Haslett for their excellent technical, cytogenetic, and radiotherapy assistance, and Miss Lynette Noble for preparation of this manuscript. We would also like to thank The Spastics Society and the Generation Trust for their financial support. Dr Juan Llerena $\mathrm{Jr}$ is supported by Action Research for the Crippled Child.

\section{References}

${ }^{1}$ Boder E. Ataxia-telangiectasia: some historic clinical and pathologic observations. Birth Defects 1975;XI(1):255-70.

2 Waldman TA. Immunological abnormalities in ataxiatelangiectasia. In: Bridges BA, Harnden DG, eds. Ataxia telangiectasia - a cellular and molecular link between cancer, neuropathology and immune deficiency. New York: Wiley, 1982:37-51.

3 Swift M, Reitnauer PJ, Morrell D, Chase CL. Breast and other cancers in families with ataxia-telangiectasia. $N$ Engl $J$ Med 1987;316:1289-94.

4 Cunliffe PN, Mann JR, Cameron AH, Roberts KD. Radiosensitivity in ataxia-telangiectasia. $B r J$ Radiol 1975; 48:374-6.

5 Murnane JP, Painter RB. Complementation of the defects in DNA synthesis in irradiated and unirradiated ataxiatelangiectasia cells. Proc Natl Acad Sci USA 1982;79:1960-3.

6 Jaspers NG, Bootsma D. Genetic heterogeneity in ataxiatelangiectasia studied by cell fusion. Proc Natl Acad Sci USA 1982;79:2641-4.

7 Chen P, Imray P, Kidson C. Gene dosage and complementation analysis of ataxia telangiectasia lymphoblastoid cell lines assayed by induced chromosome aberrations. Mutat Res 1984; 129:165-72.

${ }^{8}$ Cohen MM, Shaham M, Dagan J, Shmuell E, Kohn G. Cytogenetic investigations in families with ataxia-telangiectasia. Cytogenet Cell Genet 1975;15:338-56.

9 Taylor AMR. Cytogenetics of ataxia telangiectasia. In: Bridges BA, Harnden DG, eds. Ataxia telangiectasia - a cellular and molecular link between cancer, neuropathology and immune deficiency. New York: Wiley, 1982:53-81.

10 Aurias A, Croquette MF, Nuyts JP, Griscelli C, Dutrillaux B. New data on clonal anomalies of chromosome 14 in ataxia telangiectasia: tct $(14 ; 14)$ and inv(14). Hum Genet 1982;72:22-4.

11 McKinnon PJ. Ataxia-telangiectasia: an inherited disorder of ionizing-radiation sensitivity in man. Hum Genet 1987;75: 197-208.

12 Giannelli F, Avery JA, Blunt S. Prenatal exclusion of ataxia telangiectasia. In: Bridges BA, Harnden DG, eds. Ataxia telangiectasia - a cellular and molecular link between cancer, neuropathology and immune deficiency. New York: Wiley, 1982:393-400.

13 Shaham M, Voss R, Becker Y, Yarkoni S, Ornoy A, Kohn G. Prenatal diagnosis of ataxia telangiectasia. J Pediatr 1982;100: 134-7.

14 Schwartz S, Flannery DB, Cohen M. Tests appropriate for the prenatal diagnosis of ataxia telangiectasia. Prenat Diagn 1985;5: 9-14.

15 Auerbach AD. Prenatal diagnosis of mutagen-hypersensitivity ڤొ syndromes. Curr Probl Dermatol 1987;16:197-209.

${ }^{16}$ Fraccaro M, Simoni G, Brambati B, eds. First trimester diagnosis. Berlin: Springer, 1985.

${ }^{17}$ Modell B. Chorionic villus sampling. Evaluating safety and efficiency. Lancet 1985;i:737-40.

18 Dallapiccola B, Doria Lamba Carbone L, Ferranti G, Cristiani ML, Bricarelli FD. Monitoring of pregnancies at risk for Fanconi's anaemia by chorionic villi sampling. Acta Haematol $N$ (Basel) 1985;73:157-8.

19 Murer-Orlando M, Llerena J, Zahed L, et al. Chorionic villus sampling (CVS) in Fanconi anaemia. J Med Genet 1987;24: $245 \mathrm{~A}$.

20 Auerbach $\mathrm{AD}$, Min $\mathrm{Z}$, Ghosh $\mathrm{R}$, et al. Clastogen induced 윽 chromosomal breakage as a marker for first trimester prenatal diagnosis of Fanconi anaemia. Hum Genet 1986;73:86-8.

${ }^{21}$ Rodeck CH, Nicolaides KH, Morsman JM, McKenzie C, D Gosden CM, Gosden JR. A single operator technique for firsttrimester chorion biopsy. Lancet 1983;ii:1340-1.

22 Murer-Orlando M, Llerena J, McGuire M, et al. Chromosome banding in direct preparations of chorionic villi. Prenat Diagn 1988;8:461-9.

${ }^{23}$ Simoni G, Brambati B, Danesino C, et al. Efficient direct chromosome analyses and enzyme determinations from chorionic villi samples in the first trimester of pregnancy. Hum Genet 1983;63:349-57.

24 Murer-Orlando M, McGuire M. Short term chorionic villi and amniocentesis cultures. In: Walker JM, Pollard JW, eds. Tissue culture techniques. Methods in molecular biology. Vol 5. Clifton, NJ: The Humana Press, 1988.

${ }^{25}$ Seabright M. A rapid banding technique for human chromosomes. Lancet 1971;ii:971-2.

26 Casperson T, Zeck L, Johansson C, Modest EJ. Identification of human chromosomes by DNA-binding fluorescent agents. Chromosoma 1970;30:215-27.

27 An international system for human cytogenetic nomenclature (ISCN). Cytogenet Cell Genet 1978;21:309-402.

28 Zahed L, Murer-Orlando M, Bobrow M. Cell cycle studies in CVS. Hum Genet 1988;80:127-34.

29 Taylor AMR, Rosney CM, Campbell JB. Unusual sensitivity of ataxia telangiectasia to bleomycin. Cancer Res 1979;39:1046-50.

30 Zampetti-Bosseler F, Scott D. The response of normal and 을 ataxia-telangiectasia cells to bleomycin: relationships between chromosome damage, cell cycle delay and cell killing. Mutat Res 1985;51:89-94.

31 Arlett CF. Human DNA repair defects. $J$ Inherited Metab Dis 1986;9(suppl):69-84.

Correspondence to Dr J Llerena Jr, Division of Medical and Molecular Genetics, Paediatric $\omega$ Research Unit, 8th Floor, Guy's Tower, Guy's Hospital, London SE1 9RT. 